\title{
el llindar. ESCUELA DE OPORTUNIDADES
}

Begonya Gasch Yagüe

Fundació El Llindar. Cornellà de Llobregat

www.ellindar.org

\section{A MODO DE HISTORIA}

a Fundació El Llindar nació hace 10 años con la voluntad de trabajar con adolescentes y jóvenes y luchar por la igualdad de oportunidades en el ámbito educativo y social. Con ilusión y coraje cada día trabajamos para construir puentes para atravesar el umbral hacia un futuro posible.

En estos diez años hemos comprobado, desde la práctica del día a día con más de 2.600 adolescentes y jóvenes, que es necesario repensar el hecho educativo para que sea una experiencia posible para todos, incluyendo aquellos a los cuales el sistema educativo no acaba de dar respuesta a sus necesidades e intereses.
2. El llindar es el umbral, la frontera, el lugar de paso. Aquí es encontrarse y desear ser uno mismo. Es despertar el orgullo de ser alumno y sentirse valioso. Para conseguirlo trabajamos en base a un acompañamiento subjetivo y una orientación educativa y laboral. Alargamos los recorridos formativos, alternando formación y trabajo, apoyando su transición a la vida adulta, el retorno al sistema educativo y aumentando su empleabilidad.
UNA PRIMERA APROXIMACIÓN A MODO DE HIPÓTESIS: ES NECESARIA OTRA MIRADA Y OTRO TIEMPO.

¿Adolescentes?, ¿jóvenes?, ¿personas que encarnan todos los riesgos de nuestra sociedad? ¿Que expresan el desorden social desde dentro? ¿Personas que nos dejan entrever conflictos que no siempre son los suyos? Como dice Manuel Delgado, son la reserva del conflicto.

$Y$ entre esas adolescencias hay algunas muy vulnerables y frágiles. Aquellas trayectorias más turbulentas en que este tiempo de paso, de tránsito, donde la identidad está sin configurar, a veces resulta insoportable y va generando un profundo malestar en el adolescente. Y por allí donde pasa toma forma de conductas desafiantes, agresivas, molestando, transgrediendo toda norma y provocando el desorden social. ¿Son parte de los desheredados?, en expresión de Winnicott. Todo para encontrar un lugar donde ser. Casi podría afirmar que estos adolescentes no sólo viven en el umbral sino que son el límite.

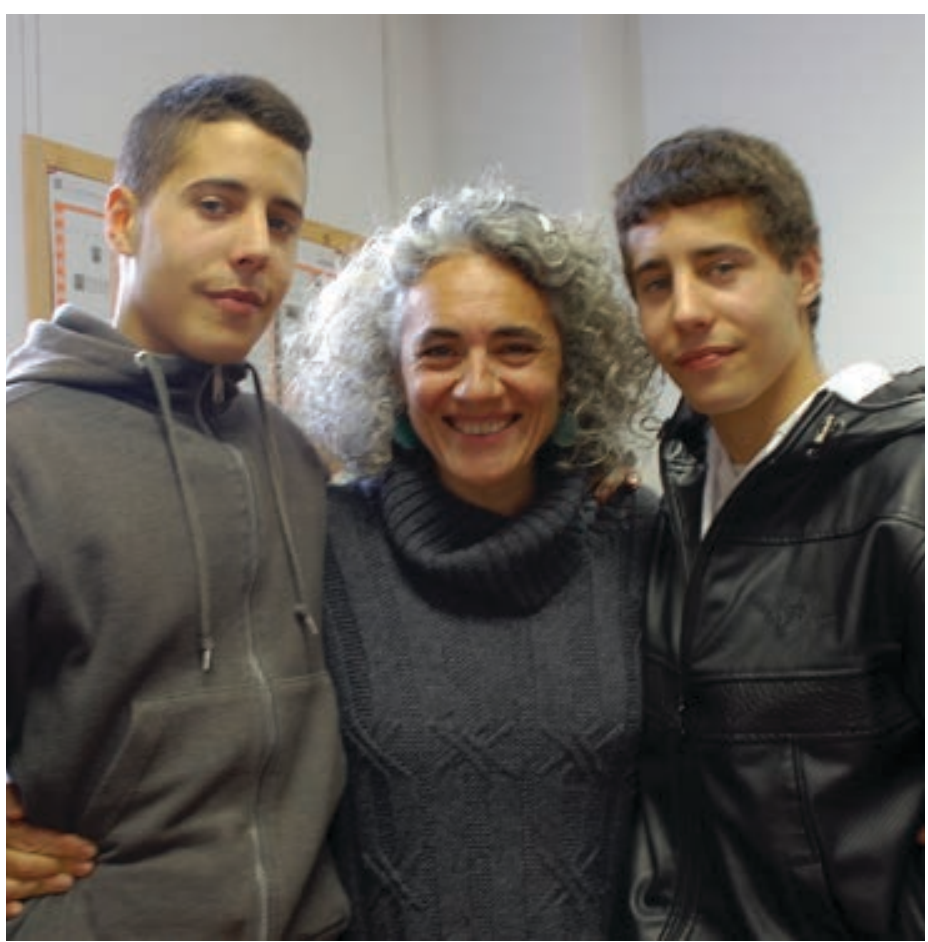

Begonya Gasch Yagüe y dos jóvenes. 
Con decisión nos hemos construido como espacio educativo que permita romper la sucesión de fracasos de los jóvenes y los adolescentes que son excluidos del sistema educativo y social. Lo hacemos a través de una propuesta educativa que alterna formación y trabajo, de calidad, cualificada, orientando, acompañando su transición a la vida adulta.

Con decisión queremos formar parte de la política educativa y hoy nos consideramos un centro de alternancia entre formación y trabajo con programas de "Segunda Oportunidad". Nos explicamos por la lógica que construye nuestro trabajo educativo, nuestra pedagogía y didáctica..., y, por encima de todo, por nuestra mirada humanizadora y singular capaz de generar itinerarios y oportunidades formativas para aquellos adolescentes y jóvenes que se han descolgado de todo circuito formativo y muchas veces descolgados de la vida.

Nos define la reinterpretación del encargo que nos hace la administración, la mayoría de las veces sujeto a la lógica de "tengo un problema, solucionadlo". Muy pocas veces, por no decir nunca, hay una propuesta verdadera que nace de políticas educativas y sociales que buscan emancipar al sujeto.

\section{¿A QuiÉnes SE diRige nUestra PROpUesta EDUCATIVA?}

Los adolescentes y jóvenes que llegan a nuestra escuela tienen en común recorridos de fracaso académico, de abandono del sistema educativo. Son jóvenes muy poco cualificados, descolgados de los circuitos formativos, con dificultades severas para afrontar y sostener un proceso de aprendizaje.

\section{¿EN QUE SE FUNDAMENTA NUESTRA POLÍTICA EDUCATIVA?}

Destacaría tres ejes básicos alrededor de los cuales construimos nuestra oferta educativa:

- Política de subjetividad.

- Educación personalizada.

- Espacios y tiempos de acompañamiento.

\section{Política de subjetividad. Entre "el uno por UNO" Y EL "PARA TODOS"}

Nos orienta una política de subjetividad para construir espacios y tiempos personalizadores, donde cada alumno construye su recorrido formativo. El éxito está en contar con cada alumno, con su particularidad, con su responsabilidad y dignidad como persona. Escuchando su singularidad le acompañamos en su proceso formativo y vital.

Apostar por una política de subjetividad quiere decir, entre otras cosas, establecer márgenes de tolerancia diferentes, encontrar el equilibrio entre la flexibilidad y los límites, intentando no caer en una mera adaptación que, por excesiva, provoque angustia o tape las crisis. Significa que la pedagogía y la didáctica, los tiempos y los espacios, el currículum, están pensados para favore- cer los itinerarios personales. Ello implica construir una estructura flexible, diversificada, con capacidad para construir recorridos diversos.

Creo que hay tres cuestiones relevantes a tener en cuenta para poder trabajar desde una política de subjetividad.

- Es esencial tener en cuenta los conocimientos previos con los que llegan estos adolescentes y jóvenes. Durante su escolaridad han residido en el quicio sin entrar a formar parte de la institución educativa. Se presentan como adolescentes y jóvenes conflictivos, no dispuestos a ser alumnos. Su energía está puesta en alguna otra cosa que poco tiene que ver con el hecho educativo, preocupados por saber quiénes son. No tienen energía para aprender. Actúan para no saber nada de su malestar y no pensar. Por lo tanto, las primeras cuestiones que orientan nuestro trabajo son: ¿cómo buscar su consentimiento para que se despierte su deseo de aprender? ¿Cómo rebajar su angustia para que pueda elaborar algunas ideas? ¿Cómo hacer para que alguien consienta ser alumno, después de años de desvinculación, de fracaso y finalmente de abandono?

- Es prioritario que el profesional pueda mirar de otra manera sus conductas, explorar qué hay detrás de las conductas agresivas, desafiantes, molestas que expresan una y otra vez - y casi siempre de la peor manera- su profundo malestar. No saben expresar su malestar, como no pueden poner palabras, actúan. Es necesario buscar una lógica a su actuar, trabajar para que el sujeto se responsabilice y tome la palabra.

- Esfuerzo continuo de la institución para salir de determinadas lógicas que pueden cronificar el malestar de los chicos y chicas, y anclarlos en el fracaso escolar y dejarlos sin futuro posible:

- La lógica de estandarización que simplifica problemas y unifica demandas.

- La lógica del protocolo que normativiza y que dice en todo momento lo que hay que hacer.

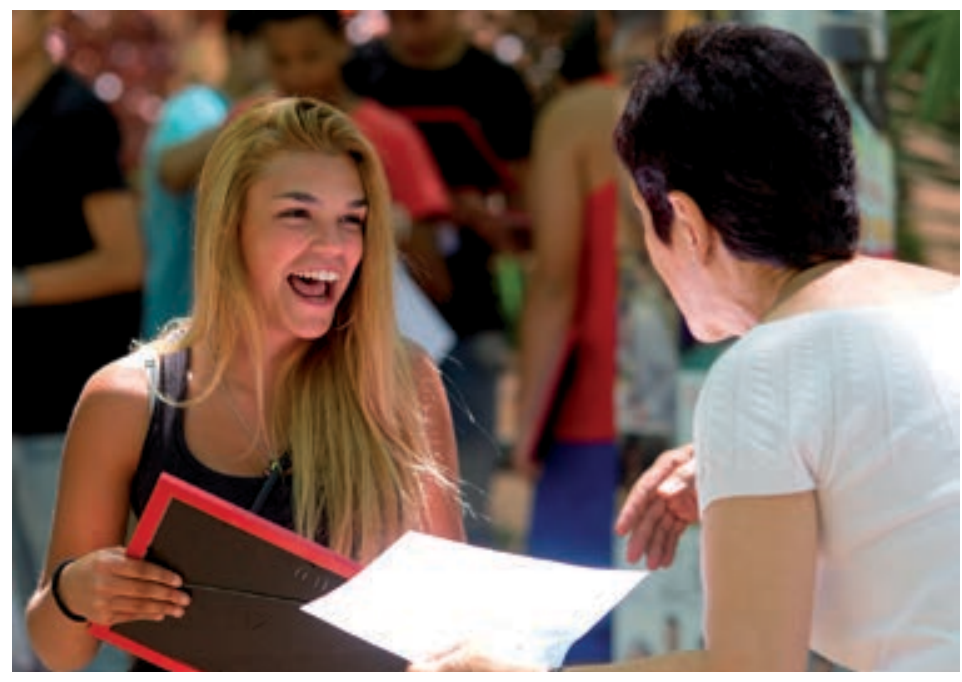

Entrega de diplomas 2013. 
Este curso escolar estamos atendiendo a 227 adolescentes y jóvenes con la siguiente oferta formativa:

- Educación Secundaria adaptada y flexible (13-16 años)

Programas educativos muy personalizados dirigidos a alumnos/as de $2^{\circ}$ ciclo de ESO que han quedado excluidos del sistema educativo. Se combina la formación básica con un amplio número de talleres manipulativos. Se orienta su futuro profesional y se trabajan las competencias transversales.

- Aula taller/Talleres de Iniciación Profesional/Programas de Diversificación Curricular.

- Formación Professional Inicial (Nivel I • 16-18 años)

Se dirigen a jóvenes sin el graduado en la ESO y con poca cualificación. Están enfocados a orientar su retorno al sistema educativo reglado en una especialidad concreta, o a la inserción en el mercado laboral.

- Especialidades: Imagen Personal/Reparación y mantenimiento de vehículos ligeros.

- Formación Professional Especializada (Nivel 2 • 18-25 años)

Se dirigen a aquellos/as jóvenes que han superado una formación inicial. Profundizan en un oficio, favoreciendo su cualificación y empleabilidad. Se combina la formación con prácticas en empresas.

- Especialidades: Imagen personal/Lampistería/Mantenimiento y rehabilitación de edificios.

- Reconéctate. Programas de éxito y retorno escolar (16-2I años)

Se dirigen a aquellos/as jóvenes que han quedado excluidos del sistema educativo. Se conciben como un puente que facilite su retorno al sistema reglado; ya sea a una Formación Profesional Inicial, o a Ciclos Formativos de Grado Medio.

- VENTALLers/Acceso a Medida/Becas de refuerzo escolar.

- La lógica del diagnóstico que obtura el hacerse preguntas y anula la responsabilidad de los sujetos (profesionales y alumnos) en vez de orientar el proceso.

- La lógica de la medicalización y la lógica de la homogeneización.

Si estas lógicas, que a su vez determinan y orientan una determinada política educativa, no nos acaban de ser útiles, entonces ¿cuál es la lógica que mueve nuestra institución educativa? Desde El Llindar en estos diez años hemos ido aprendiendo que estas lógicas no nos interesaban, que hay otra manera de pensar, enunciar; nos hemos empeñado en buscar la lógica desde la cuestión-respuesta, aprender a hacernos preguntas, ponernos a trabajar en relación a lo que no sabemos, reinventar el discurso educativo permanentemente, hacer experiencia del encuentro y del desencuentro, a tiempo y a destiempo...

\section{Educación Personalizada}

El ritmo, el estilo de aprendizaje y el nivel de cada alumno es el que guía el proceso de aprendizaje en cada espacio de trabajo, en los talleres del aula, y en los talleres profesionalizadores, garantizando las competencias básicas. Se trabaja desde la pedagogía de la responsabilidad que impulsa la autonomía individual y el apoyo del grupo.

Nos organizamos en grupos de diez alumnos y cada uno tiene un tutor que acompaña el proceso y modula los tiempos y espacios para cada alumno. Un primer tiempo es necesario para construir el vínculo afectivo y la transferencia que, poco a poco, permitirá al educador acompañar al chico para elaborar una narrativa de su situación personal, generar el consentimiento a ser alumno. Muy lentamente, éste puede empezar a transformar las conductas de actuaciones - agresiones, delitos, consumos...- en palabras y pensamientos.

Los espacios personales de encuentro, de conversación, forman parte de la programación curricular. Tiempo para transformar una queja, un sentirse víctima, una rabia, en una pregunta: ¿qué me pasa? Tiempo para construir la narración personal, el itinerario formativo y más tarde el profesional.

Es clave el consentimiento: la confianza en el adulto posibilita el cambio en el adolescente y joven y despierta su deseo de aprender.

\section{ESPACIOS DE TRABAJO DE EQUIPO \\ Y ACOMPAÑAMIENTO DE LOS PROFESIONALES}

Es importante no dejarse atrapar por la prisa que nos desorienta y por la inmediatez de las múltiples demandas $y$ actuaciones de los chicos y chicas, sus familias y de la propia administración. Para ello es imprescindible dinamizar espacios que modulen y permitan el trabajo colectivo del equipo docente. Es vital el trabajo del equipo docente en colaboración con la mirada de la

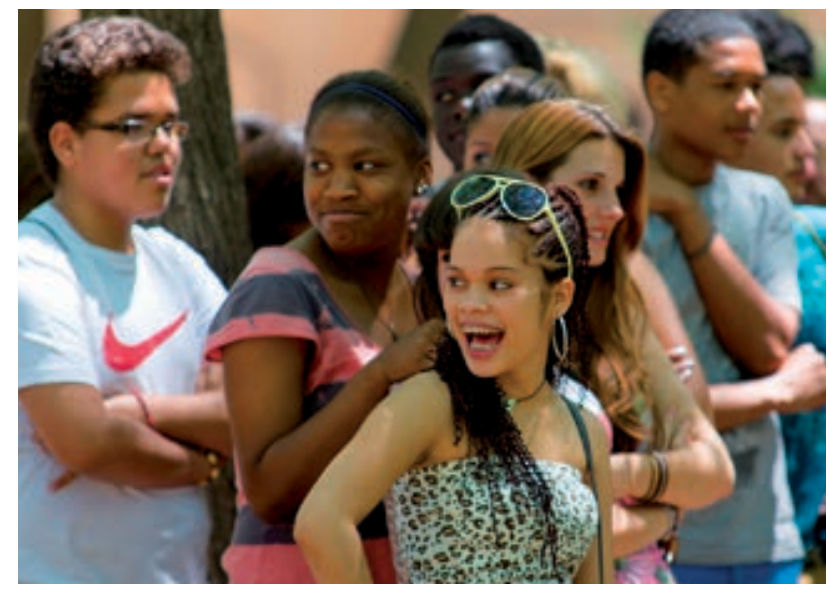

Un grupo de alumnos de El Llindar del curso 2012-2013. 
Figura I. Mapa de la oferta formativa del curso escolar 20 I3-20 I4

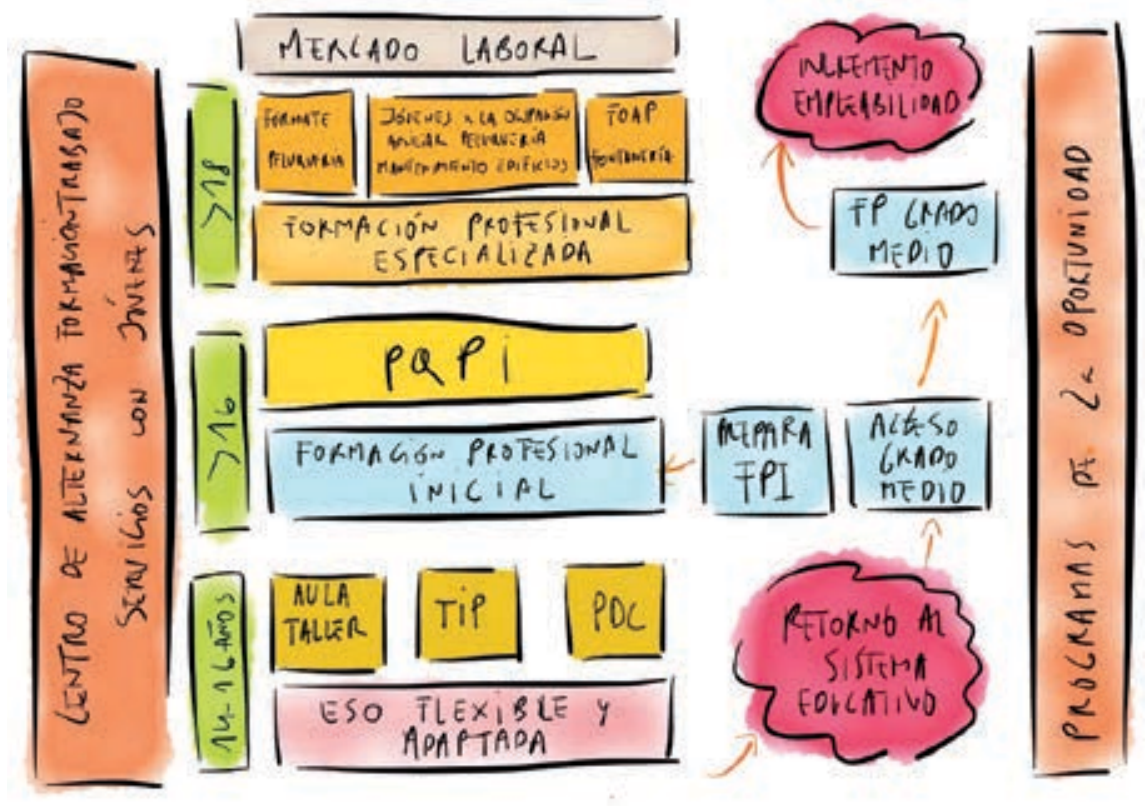

salud mental ' para saber cómo afrontar los obstáculos personales, el malestar y el sufrimiento de los alumnos, sus familias $y$ de los propios profesionales.

Así hemos ido construyendo diferentes espacios de trabajo semanal o quincenal que nos permitan introducir otro concepto de tiempo; un tiempo lógico que permita comprender antes de concluir. Esfuerzo continuo para salir de la urgencia y de la prisa, para comprender la lógica que mueve al adolescente o joven a actuar, comprender sus dificultades y no dejarnos atrapar por sus conductas; trabajo colectivo y personal para cuestionarnos y buscar cómo colaborar mejor en el proceso de subjetivación y aprendizaje del alumno.

- Espacio de construcción de casos y encuentros triangulares que generan producciones colectivas que ayudan a salvaguardar el orden educativo del centro. Espacios donde se construye la lógica de cada alumno desde su particularidad, donde se formulan hipótesis de trabajo en relación a cada alumno.

- Trabajo del equipo de maestros de taller y educadores orientados por la lógica personal de cada alumno, donde se construye la pedagogía y la didáctica de cada espacio de trabajo, se formulan hipótesis, estrategias y tácticas del equipo a nivel colectivo y personal.

- Espacios de apoyo y orientación para las familias, tanto para promover la parentalidad positiva como para facilitar la orientación y el apoyo a las dinámicas familiares $y$ a la subjetivación de retos, sufrimientos y malestares.

\section{A MODO DE CONCLUSIÓN}

EI Llindar, el umbral, un lugar de paso donde es difícil sostenerse si uno está solo y herido. Lugar de incertezas y tiempo de inseguridades. En este umbral se ha cons-

\footnotetext{
I Fundació Cassià Just.
}

truido un espacio y tiempo para la vida, para soñar un futuro posible, para reconocerse como persona. Un lugar para la experiencia positiva de existir, para adultos que los miramos con ternura y los sostenemos con firmeza. No les dejamos caer y les acompañamos un tramo de su camino, transmitiendo el deseo de saber, no dimitimos de educar, aprendemos cada día a seguir siendo educadores con los expulsados, ignorados, derivados y segregados. De ellos aprendemos a confiar y a esperar.

Somos su escuela, un lugar y un tiempo para transitar, encontrarse y desear ser ellos mismos. Ellos y nosotros nos sentimos orgullosos de nuestro proyecto compartido.

\section{Para saber más}

- Meirieu, P. (2009). Pedagogia: el deure de resisitir. Barcelona: Rosa Sensat.

- Aichrorn, A. (2006). Juventud desamparada. Barcelona: Gedisa.

- Ubieto, J. R. (2009). El trabajo en red. Barcelona: Gedisa.

- Tizıo, H. (2003). Reinventar el vínculo educativo. Barcelona: Gedisa.

- Pennac, D. (2008). Mal de escuela. Barcelona: Mondadori.

Películas

- Ferreira, P. (20I2). Los niños salvajes.

- Cantet, L. (2008). Entre les murs (La Clase).

\section{hemos hablado de:}

Talento emprendedor; aprender a emprender; proyectos; competencia emprendedora.

Este artículo fue solicitado por PADRES Y MAESTROS en julio de 2013, revisado y aceptado en diciembre de 2013 para su publicación. 